\title{
Assessing Policy Challenges and Strategies Supporting Informal Caregivers in the European Union
}

Citation for published version (APA):

Wieczorek, E., Evers, S., Kocot, E., Sowada, C., \& Pavlova, M. (2022). Assessing Policy Challenges and Strategies Supporting Informal Caregivers in the European Union. Journal of Aging \& Social Policy, 34(1), 145-160. https://doi.org/10.1080/08959420.2021.1935144

Document status and date:

Published: 02/01/2022

DOI:

10.1080/08959420.2021.1935144

Document Version:

Publisher's PDF, also known as Version of record

Document license:

Taverne

Please check the document version of this publication:

- A submitted manuscript is the version of the article upon submission and before peer-review. There can be important differences between the submitted version and the official published version of record.

People interested in the research are advised to contact the author for the final version of the publication, or visit the DOI to the publisher's website.

- The final author version and the galley proof are versions of the publication after peer review.

- The final published version features the final layout of the paper including the volume, issue and page numbers.

Link to publication

\footnotetext{
General rights rights.

- You may freely distribute the URL identifying the publication in the public portal. please follow below link for the End User Agreement:

www.umlib.nl/taverne-license

Take down policy

If you believe that this document breaches copyright please contact us at:

repository@maastrichtuniversity.nl

providing details and we will investigate your claim.
}

Copyright and moral rights for the publications made accessible in the public portal are retained by the authors and/or other copyright owners and it is a condition of accessing publications that users recognise and abide by the legal requirements associated with these

- Users may download and print one copy of any publication from the public portal for the purpose of private study or research.

- You may not further distribute the material or use it for any profit-making activity or commercial gain

If the publication is distributed under the terms of Article $25 \mathrm{fa}$ of the Dutch Copyright Act, indicated by the "Taverne" license above, 


\section{Assessing Policy Challenges and Strategies Supporting Informal Caregivers in the European Union}

\section{Estera Wieczorek, Silvia Evers, Ewa Kocot, Christoph Sowada \& Milena Pavlova}

To cite this article: Estera Wieczorek, Silvia Evers, Ewa Kocot, Christoph Sowada \& Milena Pavlova (2021): Assessing Policy Challenges and Strategies Supporting Informal Caregivers in the European Union, Journal of Aging \& Social Policy, DOI: 10.1080/08959420.2021.1935144

To link to this article: https://doi.org/10.1080/08959420.2021.1935144

曲 Published online: 15 Jun 2021.

Submit your article to this journal $\pi$

LII Article views: 333

Q View related articles $₫$

View Crossmark data $[\pi$ 


\title{
Assessing Policy Challenges and Strategies Supporting Informal Caregivers in the European Union
}

\author{
Estera Wieczorek $\mathbb{D D}^{\mathrm{a}, \mathrm{b}}$, Silvia Evers $\mathbb{D}^{\mathrm{b}}$, Ewa Kocot ${ }^{\mathrm{a}}$, Christoph Sowada ${ }^{\mathrm{a}}$, \\ and Milena Pavlovab \\ aMSc, Department of Health Economics and Social Security, Institute of Public Health, Faculty of Health \\ Sciences, Jagiellonian University Collegium Medicum, Krakow, Poland; ' $\mathrm{MSSc}$, Department of Health \\ Services Research, Faculty of Health, Medicine and Life Sciences, CAPHRI, Maastricht University, \\ Maastricht, Netherlands
}

\begin{abstract}
Cost containment and the preferences of older adults are important stimuli for encouraging the provision of informal care worldwide. Nevertheless, informal caregiving can have negative effects on caregiver's health, wellbeing, and employment opportunities. Moreover, it is questionable whether informal caregivers can substantially contribute to meeting the increasing demand for care or serve as a substitute for formally provided services. This commentary assesses strategies to remediate the negative effects of caregiving and ultimately to improve informal caregiving and to support their critical role in European long-term care systems. Cash benefits are a particularly common method of supporting informal caregivers; paid and unpaid leave, and flexible work arrangements are the most prevalent measures to support family caregivers within labor market policy, specifically. Providing training and counseling services to individuals engaged in informal care is a strategy used to support caregivers at home. Disparities in the level of support provided to informal caregivers across the European Union need to be addressed. A lack of supporting policies increases the likelihood that caregivers experience negative physical and psychosocial health problems, as well as unemployment and impoverishment.
\end{abstract}

\section{ARTICLE HISTORY}

Received 15 May 2020

Accepted 8 December 2020

\section{KEYWORDS}

Informal care; informal caregivers; long-term care; older adults; Europe; social support

\section{Introduction}

Progressive population aging in the European Union (EU) is expected to increase expenditures on long-term care (LTC) due to the increased size of the population requiring care, length of services provided, and technological advancements used in LTC (European Commission, 2012). Most EU Member States thus face strong and growing fiscal pressures within their LTC systems. In 2013, the public LTC expenditure in the EU was on average 1.6\% of Gross Domestic Product (GDP). However, by 2060, this share is estimated to increase to $2.7 \%$ of GDP (European Commission, 2019). In this context, policymakers must address the triple challenge of ensuring high-quality care

CONTACT Estera Wieczorek estera.wieczorek@uj.edu.pl 0 Jagiellonian University Collegium Medicum, Institute of Public Health, Department of Health Economics and Social Security, Skawińska 8, 31-066 Kraków, Poland 
and high rates of inclusion while upholding financial viability (Mosca et al., 2016).

The ability of the EU to address the triple challenge is hampered by a potential shortage of care professionals projected in the near future (European Commission, 2012; OECD, 2020). Therefore, all EU Member States have adopted policies to encourage home-based care and thus, "ageing in place" in order to reduce utilization of institutional LTC (Krabbe-Alkemade et al., 2020; Plöthner et al., 2019). Nonetheless, the ability of older adults to stay at home with age-related declines in capabilities may be compromised by the absence of viable caregiving options.

Older adults are likely to experience functional impairment, which ultimately leads to increased dependency (Kingston et al., 2017), i.e., the inability to carry out daily personal tasks. Increased dependency is often a consequence of sickness or frailty (Pickard, 2011). Dependent older adults who stay at home, may receive care formally and/or informally. Formal care is provided by paid professionals, while informal care generally refers to unpaid care provided by spouses, children, other relatives, friends, or other non-kin (Triantafillou et al., 2010). This care may involve help with daily living activities such as eating, bathing, and dressing, or other household activities such as cooking, cleaning, and managing medicines. Informal caregivers are also frequently responsible for the coordination and management of complex medical procedures, even though they lack the training and skills of formal care providers (Triantafillou et al., 2010).

Europe relies heavily on informal caregivers who provide the majority of LTC for older adults (Verbeek-Oudijk et al. 2014). According to Spasova et al. (2018), the high incidence and expansion of informal care are mainly attributable to the lack of accessible institutional LTC options, as well as the traditional model of intergenerational and familial relations that promotes extended periods of family caregiving before institutional placement takes place. In addition, a number of countries are increasingly moving away from institutional to home- and community-based care provided formally or informally by family and/or friends (Krabbe-Alkemade et al., 2020; Lehnert et al., 2019). This rebalancing of LTC provision stems from austerity measures intended to reduce the reliance on more expensive institutional LTC options, as well as individual's preferences for receiving care at home (Lehnert et al., 2019; Simonazzi, 2008). According to Lehnert et al. (2019), majority of older adults prefer to remain in their known physical (community, home) and social (family, friends) environment for as long as possible. These individuals declare that being able to stay in their home has a positive impact on their personal and social identity, autonomy, control, and dignity. Notably, older adults explain their preference for informally provided care with the intimate nature of the tasks performed and the expense associated with formal care provision (Lehnert et al., 2019). 
Western European nations have favored an increased use of informal care in this shift toward greater provision of care at home and in the community. By contrast, there has been a movement toward increasing the role of formal care in Central and Eastern European (CEE) countries, as family members, who have traditionally provided care in this part of Europe, are not able to meet the increased demand for care (Alders \& Schut, 2018; Hirose \& CzepulisRutkowska, 2016; Spasova et al., 2018). CEE countries, however, lack quality LTC services in both institutional and home-based care settings, which necessitates increased investments and expansion of the public infrastructures to support greater formal LTC services provision (Hirose \& Czepulis-Rutkowska, 2016).

In this commentary, we outline arguments for and against integrating programs and policies that encourage informal care in European LTC systems. Based on this, we discuss different strategies that may remediate the negative effects of informal caregiving and ultimately improve the quality of life of informal caregivers. We conclude by arguing that disparities in the level of support provided to informal caregivers across the EU need to be addressed.

\section{Arguments in favor of informal care}

The increasing number of older adults who need a higher proportion of care for longer periods is likely to put growing fiscal pressure on the system for providing long-term services and supports (Spasova et al., 2018). Demand-side factors, together with supply-side factors, such as organization and financing of the LTC system and the availability of human resources, determine public LTC expenditures. So too does the relative proportion of LTC provided in institutions versus home and in the community settings (European Commission, 2012). Encouraging greater provision of home and communitybased services can be a way to contain costs, mainly due to the fact that in some cases, providing care in institutions is more costly than providing care in the community (Simonazzi, 2008). However, it is not known to what extent and under what conditions home care is less expensive (Krabbe-Alkemade et al., 2020).

The majority of spending on LTC occurs in inpatient LTC settings (OECD, 2019). According to data for 2017 from 27 OECD countries, 62\% of government and compulsory insurance spending on LTC was attributable to inpatient care, while only $33 \%$ of spending was related to home-based LTC (OECD , 2019). The highest share of governmental and compulsory insurance spending on inpatient LTC was found in Hungary (96\%) and Iceland (91\%). Compared to 2015, only a small decline in inpatient LTC spending was observed two years later (OECD, 2019).

From the perspective of the government and other payers, informal care can be perceived as a "free" alternative to formal care, although the cost- 
effectiveness of such alternative is not well investigated at a social level. Cost containment is thus an important stimulus for encouraging the provision of informal care by governments wishing to reduce public expenditures on formal LTC services (Colombo et al., 2011). For example, it has been estimated that Finland saved 2.8 billion Euros ( $\$ 3.4$ billion) per year on formal care due to the provision of informal care (Kehusmaa et al., 2013). Without the help of informal caregivers, the Finnish public care expenditure on formal LTC would be twice as high as it is at present.

At the same time, older adults with moderate care needs prefer to "age in place", i.e. staying at home, when compared to receiving care in LTC institutions, although this preference varies depending on a range of individual and contextual factors (Council of the European Union, 2014; Lehnert et al., 2019). Taking into account older adults' preferences for receiving care at home and in the community is necessary in order to deliver person-centered care that meets individual's physical, psychological, social and spiritual needs (Morgan \& Yoder, 2011). Increased provision of informal care is one way to meet these preferences and needs.

\section{Challenges with informal care}

According to studies, informal caregiving can have positive and/or negative effects on caregivers (Oliva-Moreno et al., 2018; Swinkels et al., 2019). The burden of caregiving is a multidimensional construct that can be influenced by a range of factors including, but not limited to, ethnicity and culture, hours spent providing care, as well as care recipient's state of health and level of dependency (Di Novi et al., 2015; Oliva-Moreno et al., 2018; Roth et al., 2015; Swinkels et al., 2019). The role of culture is reflected in differences in caregiving experiences across Europe. Di Novi et al. (2015), for example, concluded that the impact of informal caregiving significantly varies across European regions and is closely related to specific cultural and social norms. In countries such as Italy, Spain, and Greece, where informal care is regarded as a familial responsibility and where the role of informal care is pivotal, caregivers likely feel high satisfaction from giving support, though there is no difference in selfassessed health between carers and non-carers (Di Novi et al., 2015). In countries such as the Netherlands, Sweden, and Denmark, where greater reliance is placed on formal support structures, carers tend to rate their own health better than non-carers do.

Lower care recipient dependency levels and lower hours spent helping with activities of daily living (ADL) have been found to have a positive impact on caregiver experiences across a range of settings (Oliva-Moreno et al., 2018). Alternatively, increasing the reliance on informal care heightens caregiver burden while incurring unwanted health and economic consequences (Bom et al., 2018; OECD, 2019). This is particularly true among caregivers providing 
care to older adults with great health needs and dependency levels (Bom et al., 2018; Oliva-Moreno et al., 2018). Providing care at home is a very demanding and stressful task that may have adverse implications for the health and mental health of carers, irrespective of the type of welfare state within which they are situated (Kaschowitz \& Brandt, 2017; Sternbeg, 2012). The burden and stress of caregiving are associated with mental health problems such as depression, anxiety, hostility, and anger (Bom et al., 2018). These negative ramifications on carers' health status are important since they may affect their ability to care for others or simply function in everyday life. Additionally, overburdened caregivers are less likely to act on their own health needs and more likely to engage in unhealthy habits such as smoking, alcohol abuse, and under-sleeping (European Commission, 2019).

From the payer's perspective, care provided by family members may seem "free" but there are opportunity costs associated with providing informal care (Pickard et al., 2017). In addition to the adverse health and mental health effects noted, caring for family members can have substantial adverse impacts on the likelihood of working and the number of hours worked (Schmitz \& Westphal, 2017). The resulting lack of stable income may, in turn, lead to impoverishment and lower pension entitlements in the future (European Commission, 2012). In a number of European countries, informal caregivers are not protected by employment contract (European Commission, 2018). Stress from foregone income and lack of entitlement, and uncertainty about the future may discourage individuals from providing unpaid care while further burdening those who already provide it (Triantafillou et al., 2010).

More fundamentally, it is questionable whether countries will be able to increase the number of informal caregivers available to meet the increased demands for care posed by population aging in the light of other societal developments. These developments include increased labor market participation of women, changes in family models such as shrinking family size, increased pension age, changing living arrangements including single-person households, rising childlessness, and higher divorce rates (He \& McHenry, 2013; Pickard, 2011). Together these trends suggest that increasingly fewer people will be available to provide unpaid, informal care over time.

Furthermore, even if informal care could be encouraged, it is questionable whether informal care can substitute for formal care, particularly, when dependent people need highly specialized care (Bonsang, 2009). Informal caregivers often do not possess the qualifications or training needed to care for older adults with complex conditions, and therefore may lack the competencies and confidence to do so (Given et al., 2008). Indeed, according to one study, many informal caregivers report being unprepared and receiving little to no guidance from LTC providers (Given et al., 2008). Family carers who lack skills may feel unprepared for the caring role and thus may cease providing care or eschew it altogether due to the accompanying distress and anxiety 
(Given et al., 2008). The resulting suboptimal care may lead to premature deterioration and an increased need for institutionalization or formal care services (European Commission, 2018).

\section{Strategies for supporting informal caregivers}

Informal caregivers are the backbone of many European countries' LTC systems. Adverse outcomes among informal caregivers can be remediated with a range of supportive measures (Lethin et al., 2016; Mosca et al., 2016). Given the crucial role of informal care in LTC, it is important to pursue strategies that enable individuals to care for dependent relatives and friends without being disadvantaged by their caregiver role.

Contextual factors such as LTC policy, labor market policy, and sociocultural norms play important roles in influencing the decision to serve as a caregiver and in supporting those who decide to provide care once that decision has been made (Broese van Groenou \& De Boer, 2016; Plöthner et al., 2019). Thus, in order to maintain the supply of family carers and support their caregiving role, a set of policies targeted at family carers is needed. There are three possible areas where governments may operate in order to support informal caregivers (Figure 1): (1) carer compensation and recognition, (2) labor market policy, and (3) carers' physical and mental wellbeing (Colombo et al., 2011; Lethin et al., 2016). Each area is discussed in turn.
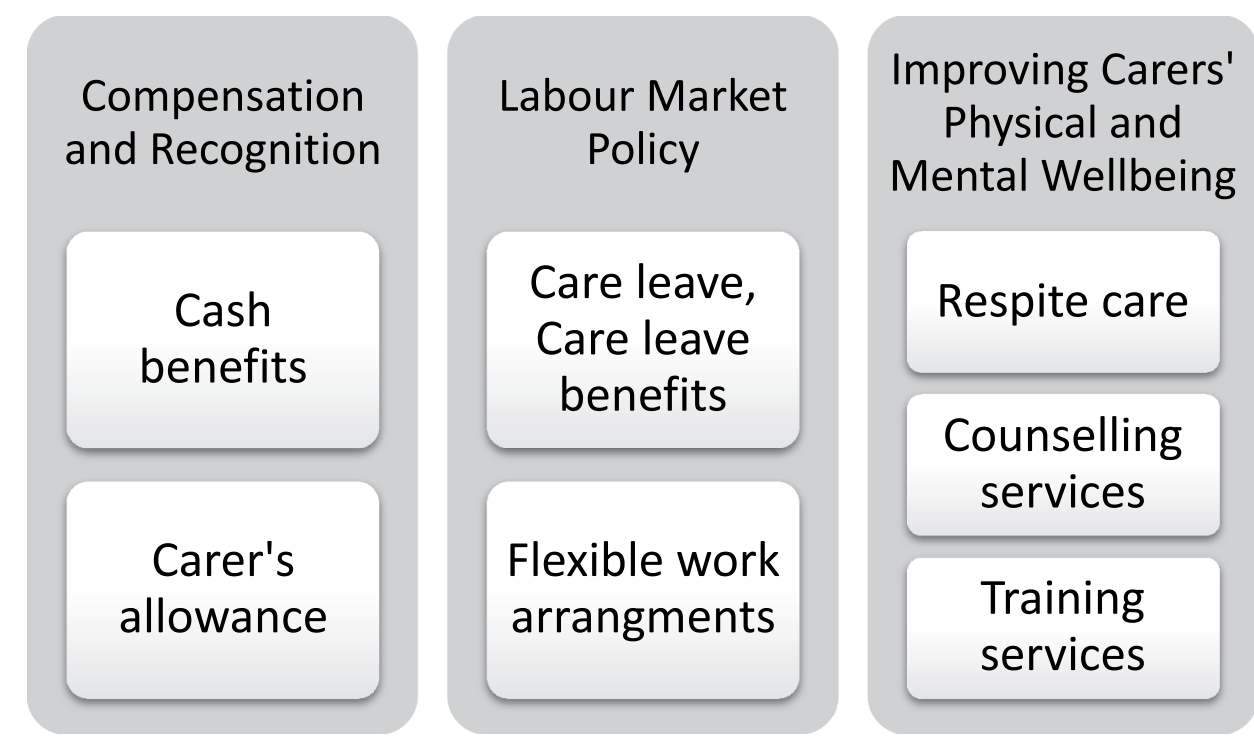

Figure 1. 


\section{Compensating and recognizing informal carers}

One form of compensating caregivers in Europe is the provision of cash benefits, paid directly to carers through a carer allowance or paid to those in need of care, who can then use that cash to compensate family carers (MISSOC, 2019). Only a handful of countries in the EU make use of direct payments exclusively (e.g., Finland, Hungary, Ireland, the United Kingdom); slightly more than half have introduced cash benefits paid to the care recipient, so-called Cash-for-Care (CfC) schemes (e.g., England, Sweden, the Netherlands) (European Commission, 2018; MISSOC, 2019; Riedel \& Kraus, 2016). A few European countries have combined the two types of cash benefit arrangements (e.g., England, the Netherlands and Sweden) (Riedel \& Kraus, 2016). Both cash benefits arrangements have their advantages and disadvantages (Colombo et al., 2011; MISSOC, 2019), as outlined below.

Direct cash benefits to dependent individuals in need of care (CfC schemes) help them purchase different types of home care from the supplier of their choice (Da Roit \& Le Bihan, 2010). These types of cash benefits are often used to pay family members to provide informal care or to relieve informal caregivers by purchasing formal home-based care (Van Den Berg \& Hassink, 2008). The aim is to increase the independence of the older adult in choosing carers, and to enable family carers to be formally hired (Da Roit \& Le Bihan, 2010).

Eligibility rules for $\mathrm{CfC}$ schemes vary among different countries, depending on: 1) the degree of care dependency, 2) income and assets, and 3) care recipient age (Courtin et al., 2014; European Commission, 2018). Portugal, Greece and the Netherlands do not set minimum levels of dependency to obtain cash benefits, only France has established an age limit on access to benefits (MISSOC, 2019). Some countries permit care recipients to hire their spouses (e.g., Denmark, Poland, Bulgaria); in France, care recipients can hire spouses to provide care only under certain, limited circumstances, as they are already responsible under the law to provide assistance to their partners (MISSOC, 2019).

There are several possible shortcomings to promoting informal care through the provision of cash benefits to care recipients. This approach makes carers financially dependent on those in need of care who are providing the compensation. This could be a particular problem in countries where family caregivers are not protected by work contracts and are not entitled to holidays, sick leave, or pension rights (e.g., the Czech Republic, Germany, Spain) (European Commission, 2019; MISSOC, 2019). This is in contrast to countries such as the Netherlands, where informal caregivers paid for by cash benefits are protected by a work contract and are entitled to social security benefits (Alders \& Schut, 2018; European Commission, 2018). Additionally, there is concern that $\mathrm{CfC}$ schemes risk monetizing family relations. This may 
result in situations where care recipients select among family members who compete for the paid caregiving role (Colombo et al., 2011).

The alternative direct cash benefit arrangement attempts to compensate carers for reduced working hours or for any costs incurred as a result of caretaking. This arrangement exists in the Scandinavian countries where municipalities employ family caregivers directly and pay them a salary. Variations in the eligibility criteria and amount of the care's allowance exist across countries offering direct cash benefits to carers (Courtin et al., 2014). Such benefits are usually granted in order to keep dependent individuals at home for as long as possible (Colombo et al., 2011). However, direct cash benefits to carers may over-incentivize informal care provision by, for example, leading carers to limit or eliminate hours working outside their home (Colombo et al., 2011), which can negatively affect labor supply. It is therefore important for policymakers to carefully consider the size and duration of direct cash benefits to assure that carers are compensated but not encouraged to drop out of the labor market (European Commission, 2019).

Several EU countries, largely concentrated in some Eastern and Southern Europe, have introduced limited to no cash benefit arrangements to date to support informal caregivers (Courtin et al., 2014). Informal care is common in Poland, for example, but a nursing benefit which can be used to pay family members, is only available to pensioners over 75 years of age, irrespective of their need of care, and was as low as 215.84 PLN (\$55) per month in 2019. In addition, the care supplement, a universal benefit to individuals 75 and older, was just 222 PLN (\$58) per month in 2019, again, irrespective of the need for care (MISSOC, 2019; Riedel \& Kraus, 2016). These amounts are too low to adequately compensate family members for the time and expenses associated with caregiving. In Romania, older adults and their carers are not eligible for cash benefits in any form, even though those in need of care mostly rely on informal care (European Commission, 2019). Similarly, in Bulgaria, although informal care is common, it is not financially encouraged, and family members need to bear direct and indirect costs related to caring without governmental assistance. Cash benefits in the form of care provision allowances are available in Spain but they are not available in the form of a carer allowance (Bover, 2011). A similar situation can be found in Italy where CfC schemes only include cash benefits to dependent persons (MISSOC, 2019).

\section{Labor market policy}

Providing informal care to an older family member while remaining professionally active may be difficult, especially if there are also other dependents (children) that require care. Some individuals decide to reduce their work hours or even drop out of the labor market in order to provide care for an aging relative (Lilly et al., 2007). Labor market policy is thus another way to 
promote and support informal caregivers. In many European countries, employees are able to take unpaid leave in order to care for dependent persons. Countries allow carers to take varying lengths of paid leave if necessary. Such arrangements enable individuals to retain employment and income while attending to their caregiving duties (European Commission, 2012, 2018). A disadvantage of this approach is that in some cases, care leaves are only available to those caring for older adults with terminal illnesses, which neglects the care needs of individuals with non-terminal diseases, who also require considerable care (Colombo et al., 2011).

Austria strongly supports carers who do not want to quit their formal employment while caring for an older relative. Under the Care Allowance Act, caregivers are allowed to make use of full-time or part-time care leave. Additionally, this policy enables carers to take a so-called family hospice leave if an older family member is terminally ill (Schmidt et al., 2016). Individuals who decide to stay at home and take on a caregiving responsibility may be eligible to receive care leave benefits for up to three months. Care leave benefits in Austria are income-related and equal to the amount of unemployment benefit (European Commission, 2019; MISSOC, 2019). The Netherlands offers paid emergency leaves that enable caregivers to stay at home for a few days in the case of a death or sudden illness; to arrange paid short-term leaves of up to 10 days a year in order to provide care for older adults, at $70 \%$ earnings; and to have long-term term unpaid leaves. In Belgium, carers may reduce their working hours for up to 36 months in order to support seriously ill relatives. The amount of benefit varies based on age, civil status and years of employment. In addition, carers are entitled to a career break in order to provide medical assistance to an ill dependent or to provide palliative care. The length of the career break may be up to 24 months for complete discontinuation and 48 months for partial discontinuation per caregiving episode (European Commission, 2016; MISSOC, 2019).

Another form of supporting policy that enables caregivers to combine their caring responsibilities with paid work is the introduction of flexible work arrangements. Flexible working hours enable caregivers to retain their job while accommodating the care needs of dependents. The availability of parttime jobs varies greatly between EU Member States but even when part-time jobs are available, only a small share of them are filled by caregivers (Colombo et al., 2011; Courtin et al., 2014). In the Netherlands, most companies (89\%) offer some part-time positions but less than $5 \%$ of those positions are occupied by caregivers. In Greece, only $16 \%$ of companies have part-timers, out of which just $1 \%$ is used for care reasons. Part-time work is more frequently requested in the context of child care than long-term care. Also, there is a substantial variability among EU Member States when it comes to the duration of part-time work, which may be requested for care reasons and the possibility of reverting back to subsequent full-time employment. In 
Germany, for example, individuals may reduce their working hours for a duration of 24 months, while in Austria, it is only up to 3 months (MISSOC, 2019).

It is undeniable that flexible work arrangements help carers balance work and caretaking. It is important, however, to remember that caring for an older adult is unpredictable in duration and intensity. Furthermore, some illnesses may be episodic in nature and require carers to divide leaves and/or periods of part-time employment over several occurrences. Under circumstances such as these, other forms of flexible work arrangements may be preferable, for example, allowing carers to decide their work schedule on a week-to-week basis during periods when caregiving demands are particularly unpredictable (Colombo et al., 2011). To meet the growing caregiving demands of an aging population it is therefore important to introduce mechanisms within the labor market to enable carers to combine paid work and caregiving (Schmidt et al., 2016).

\section{Improving carers' physical and mental wellbeing}

As mentioned previously, informal caregiving is associated with negative physical and mental health outcomes. Policies have thus been introduced to relieve some of the stress experienced by family carers. These policies range from respite care to counseling services and assistance coordinating help (Courtin et al., 2014).

Respite care is considered a fundamental form of support for informal caregivers. The pivotal goal of respite care is to reduce caregivers' burden and stress by providing breaks from regular caring duties through the use of alternative care arrangements, including in-home care, adult day services, and overnight care (Zarit et al., 2017). Respite care may take place in different settings, including within the community or institutions, and can be provided by different agents such as nurses, family, or friends (Colombo et al., 2011). Providing breaks to informal caregivers has multiple benefits for their health and wellbeing, which, in turn, enables them to take care of their dependents for longer than otherwise possible without those pauses (Vandepitte et al., 2016).

Despite its benefits, it has been reported that a high proportion of informal caregivers do not make use of respite care. One reason is limited access to and the high cost of respite care (Colombo et al., 2011). Another reason is the belief that respite care services negatively impact care recipients (Phillipson et al., 2013). Thus, it is necessary to introduce policies that make respite care more available and accessible to those who need it (Colombo et al., 2011). Not all countries in the EU (e.g., Poland and Bulgaria) grant legal entitlement to respite care. Moreover, short-term respite care is financed directly by families in most countries, with subsidies reserved for the lowest income individuals. 
There are exceptions, however. Germany and Austria, for example, provides financing for respite care for up to four weeks (MISSOC, 2019).

Counseling and training services are also an important way to support informal caregivers. Access to support from health care and social services may not only improve the wellbeing of the caregiver but may also lead to improved care for the elder. Suhonen et al. (2015), for example, found that some family caregivers lack knowledge regarding the disease, prognosis, and care routines for patients with dementia. This lack of knowledge suggests that counseling and training services that empower carers to provide care at home could prove essential in enabling them to successfully assume their caregiving responsibilities (OECD, 2015).

In the EU, most training and social support services are provided at the local level by NGOs (non-governmental organizations) and the private sector. Nevertheless, in some countries more comprehensive and integrated counseling systems can be found (MISSOC, 2019). Sweden provides family carers with innovative technological solutions such as e-care, e-health, peer support, and e-learning about caregiving. These services help carers cope with their caregiving role. Additionally, in some parts of Sweden, there are support groups and centers for caregivers. Within those groups, caregivers may share their experiences, frustrations, and problems with other carers and professionals. The Dutch government uses a preventive counseling and support approach where social workers carry out house visits, provide information to carers, and follow-up. In Spain, caregivers have access to online platforms that provide them with assistance in their caregiving role (Colombo et al., 2011). The provision of counseling support to family carers is essential not only for the carer, but also for ensuring the quality of care provided (Courtin et al., 2014).

\section{Conclusion}

Over the past decade, many European countries have tried to encourage the provision of informal LTC. Cost-containment is one of the reasons for this shift. Evidence has shown that increased availability of informal care and home-based support significantly decreases public care expenditures (Kehusmaa et al., 2013). Without adequate strategies to address caregivers' needs, however, the increased reliance on informal care may have negative impacts on both caregivers and care-recipients. Overburdened caregivers are more likely to suffer from poor physical and mental health. Moreover, without appropriate labor market policy, family carers are likely to reduce working hours or drop out of the labor market with adverse consequences for their economic wellbeing. Given these challenges, policymakers need to focus on minimizing the negative effects of caregiving through the introduction of supportive strategies that involve compensating and recognizing carers, 
offering paid/unpaid leave, promoting flexible work arrangements, and providing respite care and counseling services.

Cash benefits are a particularly common method of supporting informal caregivers. Cash benefits are often used to pay a family member to provide care and have multiple advantages, including promoting clients' freedom of choice and relieving the financial burden on carers. Furthermore, many CfC schemes allow beneficiaries to employ and compensate relatives, thus "formalizing" the informal caregiving relationship. Paid and unpaid leave and flexible work arrangements enable carers to stay professionally active and have stable incomes. Providing training and counseling supports informal caregivers by providing them with the requisite skills and knowledge needed to perform their caregiving duties successfully.

Some EU countries, e.g., Sweden, Denmark, and the Netherlands have a more developed structure for supporting informal caregivers than others. Other EU countries, however, have yet to implement comprehensive approaches to supporting unpaid caregivers, while other countries have only made modest progress. Therefore, it is critical that policymakers accompany policies intended to promote "ageing in place" with careful consideration of how best to allocate responsibilities and funding across the formal and informal care sectors. Stronger support for informal caregiving is especially important to remediate the negative effects of caregiving and ultimately improve the lives and experiences of informal caregivers and the older adults they are caring for.

There are, however, challenges for enacting strong caregiver supporting policies related to social norms about gender, family, home, and personal responsibility. Traditional norms about family responsibility to provide care to family members when needed, can prevent informal caregivers from seeking support while concealing the need of supporting policies (Levitsky, 2014). Even if such policies are implemented, they can drift in a different direction depending on the context and stakeholders involved. The notion of policy drift explains that institutional changes constantly occur, and they can shift policy effects in directions not intended when originally adopted (Hacker, 2004). An example could be the introduction of a CfC scheme previously non-existing in the country, which presents a major formal revision of existing policy implemented with the aim to support informal caregivers. A CfC scheme has however the potential to over incentivize informal care provision and reduce the need of formal care. This might discourage care institutions to develop and expand their home-based care services, which on the long-run might reduce the supply of formal home-based care and increase the burthen for informal care givers even though these effects have not been the policy intention. Furthermore, Rocco (2017) explains that political and policy barriers related to partisanship, institutional veto points, and the cost of policy updating may impact the broad patterns of policy drift that takes place, as well as the scope of 
policy change possible. The latter, in particular, suggests that minor and less costly legislative and administrative changes, like incremental adjustments in existing support programs, are more likely to be promulgated than major expensive and significant changes, like adopting an entirely new caregiver support program. Additionally, context-specific changes in demography, technology, or economic conditions may have implications for existing policies and may expose informal caregivers to economic and social risks such as unemployment or limited access to social benefits. Thus, it is important to adapt policies to changing environments (Hacker, 2004).

Finally, policymakers should keep in mind that informal care will not solve the issue of demand-supply imbalance in LTC. Even though countries may encourage informal care, the number of caregivers will continue to shrink due to declining birth rates and will be insufficient due to the increasing agedependency ratio. Formal care provision should be enhanced as well. Nevertheless, informal caregivers will continue to play an important role, and their health and wellbeing need to be protected, in part, by addressing disparities in the level of support provided across the EU.

\section{Key points}

- Cost containment and the preferences of older adults are important stimuli for encouraging the provision of informal care.

- Unsupported informal caregivers experience physical and psychosocial health problems, unemployment, and impoverishment.

- Disparities exist in the level of support provided to informal caregivers across the European Union.

\section{Disclosure of potential conflicts of interest}

No potential conflict of interest was reported by the author(s).

\section{ORCID}

Estera Wieczorek (D) http://orcid.org/0000-0003-4013-7493

Silvia Evers (D) http://orcid.org/0000-0003-1026-570X

\section{References}

Alders, P., \& Schut, F. (2018). Trends in ageing and ageing-in-place and the future market for institutional care: Scenarios and policy implications. Health Economics, Policy and Law, 14 (1), 82-100. https://doi.org/10.1017/s1744133118000129

Bevans, M., \& Sternberg, E. (2012). Caregiving Burden, Stress, and Health Effects Among Family Caregivers of Adult Cancer Patients. JAMA, 307(4). doi: 10.1001/jama.2012.29 
Bom, J., Bakx, P., Schut, F., \& van Doorslaer, E. (2018). The impact of informal caregiving for older adults on the health of various types of caregivers: A systematic review. The Gerontologist, 59(5), e629-e642. https://doi.org/10.1093/geront/gny137

Bonsang, E. (2009). Does informal care from children to their elderly parents substitute for formal care in Europe? Journal of Health Economics, 28(1), 143-154. https://doi.org/10.1016/ j.jhealeco.2008.09.002

Bover, A. (2011). Economic crisis, austerity discourses and caregiving: how to remain relevant through engagement and social justice. Nursing Inquiry, 18(3), 188-190. doi: 10.1111/j.14401800.2011.00570.x

Broese van Groenou, M., \& De Boer, A. (2016). Providing informal care in a changing society. European Journal of Ageing, 13(3), 271-279. http://dx.doi.org/10.1007/s10433-016-0370-7

Colombo, F. (2011), Help wanted? Providing and paying for long-term care. OECD Publishing. www.oecd.org/health/longtermcare/helpwanted

Council of the European Union. (2014). Adequate social protection for long-term care needs in an ageing society. Social Protection Committee.

Courtin, E., Jemiai, N., \& Mossialos, E. (2014). Mapping support policies for informal carers across the European Union. Health Policy, 118(1), 84-94. https://doi.org/10.1016/j.health pol.2014.07.013

Da Roit, B., \& Le Bihan, B. (2010). Similar and yet so different: Cash-for-Care in six European countries' long-term care policies. Milbank Quarterly, 88(3), 286-309. https://doi.org/10. 1111/j.1468-0009.2010.00601.x

Di Novi, C., Jacobs, R., \& Migheli, M. (2015). The quality of life of female informal caregivers: From Scandinavia to the Mediterranean sea. European Journal of Population, 31(3), 309-333. https://doi.org/10.1007/s10680-014-9336-7

European Commission. (2012). European economy. Long-term care: Need, use and expenditure in the EU-27. Publications Office of the European Union.

European Commission. (2016). ESPN thematic report on work-life balance measures for persons of working age with dependent relatives.

European Commission. (2018). Informal care in Europe. Exploring formalisation, availability and quality. Publications Office of the European Union.

European Commission. (2019). Joint report on health care and long-term care systems and fiscal sustainability - country documents. Publication Office of the European Union.

Given, B., Sherwood, P., \& Given, C. (2008). What knowledge and skills do caregivers need? AJN, American Journal of Nursing, 108(Supplement), 28-34. https://doi.org/10.1097/01.naj. 0000336408.52872.d2

Hacker, J. (2004). Privatizing risk without privatizing the welfare state: The hidden politics of social policy retrenchment in the United States. American Political Science Review, 98(2), 243-260. https://doi.org/10.1017/s0003055404001121

He, D., \& McHenry, P. (2013). Does labor force participation reduce informal caregiving? SSRN Electronic Journal. https://doi.org/10.2139/ssrn.2292700

Hirose, K., \& Czepulis-Rutkowska, Z. (2016). Challenges in long-term care of the elderly in central and Eastern Europe. International Labour Organization.

Kaschowitz, J., \& Brandt, M. (2017). Health effects of informal caregiving across Europe: A longitudinal approach. Social Science \&Medicine, 173, 72-80. https://doi.org/10.1016/j. socscimed.2016.11.036

Kehusmaa, S., Autti-Rämö, I., Helenius, H., \& Rissanen, P. (2013). Does informal care reduce public care expenditure on elderly care? Estimates based on Finland's Age Study. BMC Health Services Research, 13(1). https://doi.org/10.1186/1472-6963-13-317

Kingston, A., Wohland, P., Wittenberg, R., Robinson, L., Brayne, C., Matthews, F., Jagger, C., Green, E., Gao, L., Barnes, R., Arthur, A., Baldwin, C., Barnes, L. E., Brayne, C., Comas- 
Herrera, A., Dening, T., Forster, G., Harrison, S., Ince, P. G., Jagger, C., \& Weller, R. (2017). Is late-life dependency increasing or not? A comparison of the Cognitive Function and Ageing Studies (CFAS). The Lancet, 390(10103), 1676-1684. https://doi.org/10.1016/s01406736(17)31575-1

Krabbe-Alkemade, Y., Makai, P., Shestalova, V., \& Voesenek, T. (2020). Containing or shifting? Health expenditure decomposition for the aging Dutch population after a major reform. Health Policy, 124(3), 268-274. https://doi.org/10.1016/j.healthpol.2019.12.016

Lehnert, T., Heuchert, M., Hussain, K., \& Konig, H. (2019). Stated preferences for long-term care: A literature review. Ageing and Society, 39(9), 1873-1913. https://doi.org/10.1017/ s0144686x18000314

Lethin, C., Leino-Kilpi, H., Roe, B., Soto, M., Saks, K., Stephan, A., Zwakhalen, S., Zabalegui, A., \& Karlsson, S. (2016). Formal support for informal caregivers to older persons with dementia through the course of the disease: An exploratory, cross-sectional study. $B M C$ Geriatrics, 16(1), 1. https://doi.org/10.1186/s12877-016-0210-9

Levitsky, S. (2014). Caring for our own: Why there is no political demand for new American social welfare rights (1st ed.). Oxford University Press.

Lilly, M., Laporte, A., \& Coyte, P. (2007). Labor market work and home care's unpaid caregivers: A systematic review of labor force participation rates, predictors of labor market withdrawal, and hours of work. Milbank Quarterly, 85(4), 641-690. https://doi.org/10.1111/ j.1468-0009.2007.00504.x

MISSOC. (2019). MISSOC comparative tables, MISSOC database. https://www.missoc.org/ missoc-database/comparative-tables/results/

Morgan, S., \& Yoder, L. (2011). A concept analysis of person-centered care. Journal of Holistic Nursing, 30(1), 6-15. https://doi.org/10.1177/0898010111412189

Mosca, I., van der Wees, P., Mot, E., Wammes, J., \& Jeurissen, P. (2016). Sustainability of long-term care: Puzzling tasks ahead for policy-makers. International Journal of Health Policy and Management, 6(4), 195-205. https://doi.org/10.15171/ijhpm.2016.109

OECD. (2015). Health at a Glance 2015: OECD indicators. http://dx.doi.org/10.1787/health_ glance-2015-en

OECD. (2019). Health at a Glance 2019: OECD indicators. https://doi.org/10.1787/4dd50c09en

OECD. (2020). Who cares? Attracting and retaining care workers for the elderly. https://doi.org/ 10.1787/92c0ef68-en

Oliva-Moreno, J., Peña-Longobardo, L., Mar, J., Masjuan, J., Soulard, S., Gonzalez-Rojas, N., Becerra, V., Casado, M. Á., Torres, C., Yebenes, M., Quintana, M., \& Alvarez-Sabín, J. (2018). Determinants of informal care, burden, and risk of burnout in caregivers of stroke survivors. Stroke, 49(1), 140-146. https://doi.org/10.1161/strokeaha.117.017575

Phillipson, L., Magee, C., \& Jones, S. (2013). Why carers of people with dementia do not utilize out-of-home respite services. Health \& Social Care in the Community, 21(4), 411-422. https://doi.org/10.1111/hsc. 12030

Pickard, L. (2011). The supply of informal care in Europe (ENEPRI Research Report No. 94). ENEPRI \& ANCIEN. www.ceps.be/book/supply-informal-care-europe .

Pickard, L., King, D., Brimblecombe, N., \& Knapp, M. (2017). Public expenditure costs of carers leaving employment in England, 2015/2016. Health \& Social Care in the Community, 26(1), 132-142. https://doi.org/10.1111/hsc.12486

Plöthner, M., Schmidt, K., de Jong, L., Zeidler, J., \& Damm, K. (2019). Needs and preferences of informal caregivers regarding outpatient care for the elderly: A systematic literature review. BMC Geriatrics, 19(1), 1. https://doi.org/10.1186/s12877-019-1068-4 
Riedel, M., \& Kraus, M. (2016). Differences and similarities in monetary benefits for informal care in old and new EU member states. International Journal of Social Welfare, 25(1), 7-17. https://doi.org/10.1111/ijsw.12157

Rocco, P. (2017). Informal caregiving and the politics of policy drift in the United States. Journal of Aging \& Social Policy, 29(5), 413-432. https://doi.org/10.1080/08959420.2017. 1280748

Roth, D., Fredman, L., \& Haley, W. (2015). informal caregiving and its impact on health: A reappraisal from population-based studies. The Gerontologist, 55(2), 309-319. https://doi. org/10.1093/geront/gnu177

Schmidt, A., Fuchs, M., \& Rodrigues, R. (2016). Policy Brief September 2016: Juggling family and work - Leaves from work to care informally for frail or sick family members - An international perspective. European Centre for Social Welfare Policy and Research.

Schmitz, H., \& Westphal, M. (2017). Informal care and long-term labor market outcomes. Journal of Health Economics, 56, 1-18. https://doi.org/10.1016/j.jhealeco.2017.09.002

Simonazzi, A. (2008). Care regimes and national employment models. Cambridge Journal of Economics, 33(2), 211-232. http://dx.doi.org/10.1093/cje/ben043

Spasova, S., Baeten, R., Coster, S., Ghailani, D., Peña-Casas, R., \& Vanhercke, B. (2018). Challenges in long-term care in Europe. A study of national policies (European Social Policy Network (ESPN)). European Commission.

Suhonen, R., Stolt, M., Koskenniemi, J., \& Leino-Kilpi, H. (2015). Right for knowledge - The perspective of significant others of persons with memory disorders. Scandinavian Journal of Caring Sciences, 29(1), 83-92. https://doi.org/10.1111/scs.12132

Swinkels, J., van Tilburg, T., Verbakel, E., \& van Groenou, M. (2019). Explaining the gender gap in the caregiving burden of partner caregivers. Journal of Gerontology. Series B, Psychological Sciences and Social Sciences, 74(2), 309-317. doi: 10.1093/geronb/gbx036

Triantafillou, J. (2010). Informal care in the long-term care system. European Overview paper. Athens/Vienna: Interlinks.

Van den Berg, B., \& Hassink, W. (2008). Cash benefits in long-term home care. Health Policy, 88(2-3), 209-221. https://doi.org/10.1016/j.healthpol.2008.03.010

Vandepitte, S., Van Den Noortgate, N., Putman, K., Verhaeghe, S., Verdonck, C., \& Annemans, L. (2016). Effectiveness of respite care in supporting informal caregivers of persons with dementia: A systematic review. International Journal of Geriatric Psychiatry, 31(12), 1277-1288. https://doi.org/10.1002/gps.4504

Zarit, S., Bangerter, L., Liu, Y., \& Rovine, M. (2017). Exploring the benefits of respite services to family caregivers: Methodological issues and current findings. Aging \& Mental Health, 21(3), 224-231. https://doi.org/10.1080/13607863.2015.1128881 